\title{
Price Discovery from the Chinese A-Share Market: Trend Break Tests Using the Perron Mixed Model C
}

\author{
Gaolu Zou ${ }^{1, *}$, Yan Xing ${ }^{2}$ and K. W. Chau ${ }^{3}$ \\ ${ }^{1}$ School of Tourism and Economic Management, Chengdu University, Chengdu, China \\ ${ }^{2}$ Chengdu Academy of Social Sciences, Chengdu, China \\ ${ }^{3}$ The Ronald Coase Center for Property Rights Research, The University of Hong Kong, Hong \\ Kong \\ e-mail: zougaolu@vip.163.com, yanxing0604@163.com, hrrbckw@hku.hk
}

Keywords: break date, informationally efficient, shock, A-share market, trend function, unit root, time series.

\begin{abstract}
We argue that in 2007, the Chinese A-share market held a significant change in its entire progressing process. The China Petroleum listing may be a noteworthy event causing the trend change. The paper aims to test whether or not a structural break occurred in the stochastic trend of stock index data. We employed the Shanghai Composite Index and the Shenzhen Component Index series. Data spans the period from 1992M01-2014M12. Tests used the Perron mixed Model C. Integrated and break-date tests are data-dependent and treat the break point varibale to be endogenous. Tests suggest that a noteworthy trend shift in the Chinese A-stock market indeed took place in early 2007. Thus, a significant macroeconomic event that could change the market path may be perceived based on the stock index change. Further tests for two Sichuan and Chongqing real estate firm stock prices did not support a significant fiscal and tax rumor shock. Additionally, our finding indicates that the market responds quickly and markedly to a shock and thus to some extent the A-Share market follows the efficient market hypothesis (EMH). So, investors hardly benefit from transactions in the Chinese A-stock market simply by historical data.
\end{abstract}

\section{Introduction}

Stock investors in China concern changes mostly in the Shanghai Composite Index on the Shanghai Stock Exchange and the Shenzhen Component Index on the Shenzhen Stock Exchange. Evidence of real estate portfolio diversification benefits on the stock exchange in China is suggested [1]. The figure for the Shanghai Composite Index on 16 July 2007 reached the summit 6124 as compared with those throughout the entire A-share index history. We plotted the stock price index (Fig. 1). By simply looking at the index curves, we postulate that both the Shanghai Composite Index and Shenzhen Component Index Component Index appear to contain a significant structural change occurred around October 2007. Therefore, this paper aims to test for the structural break in the Chinese A-share market. Using the daily data from 1992 to 2004, the previous study suggests a break date in December 1999 for the Shanghai share market price index and in May 1999 for the Shenzhen share market price index, respectively [2]. However, we used the monthly data from 1992 to 2014.

Theoretically, a change in the stochastic trend of the data is defined as a structural break [3]. Perron (1989) argues that significant historical events (e.g., the 1929 Great Crash) can lead to a shift in the trend function of the data. Though we seldom precisely know what events (shocks) cause the change a priori, the break-date tests can detect a shift in a time series and accordingly those events or shocks may be inferred.

Also, if an event causes an instant variation in the stock price, the market may follow the efficient market hypothesis (EMH) [4-8]. However, a huge literature indicates the inefficiency of stock price indices or markets $[9,10]$, implying that investors can benefit from stock investments. The S\&P 500 long-run price structure [11], the FTSE 30 share index on the London Stock 
Exchange [12], stock prices in Athens [13], and the monthly prices in the Asia-Pacific equity markets [14] are inconsistent with the random walk hypothesis. However, the Hang Seng Index on the Hong Kong Stock Exchange follows a random walk, implying that the index maintains the weak-form efficiency [15]. Also, the Australian and New Zealand share markets are weak-form efficient [16], or semi-strong efficient [17]. The UK FTSE100 futures (stock index futures) is informationally weak-form efficient [18].

In Section IV, following the data-dependent rule and considering the shift to be endogenous, break-date tests suggest a change occurred in early 2007 in the stock price series, implying that the Chinese A-stock market is efficient with respect to a significant event. So, theoretically, based on the stock price variation, macroeconomists may perceive the significant historical event that could change the stock growth path. In practice, security investors can know when the trend diverted from the former route, which is essential to long-term investments in shares.

\section{Methodology}

A break date is assumed to be known a priori [3] and so the break variable is treated as exogenous. However, empirical tests based on a given break date are often unrealistic and so receive severe criticism [19-21]. Hence, in this paper, the break date is assumed to be unknown priori, i.e., we consider the shift variable to be endogenous [22-24]. The mixed and innovational outlier (IO) Model C simultaneously allows for a change in the level (intercept) as well as a change in the slope of the trend function [3, 23, 25]. By looking at the curves in Fig. 1, we learn that around October 2007, a change may take place in the level as well as on the slope. Hence, tests adopted the mixed IO Model C. Sen (2003) suggests that the mixed model is more appropriate given an unknown break date [26]. The null hypothesis is that the series has a unit root. The alternative is trend-stationary. The mixed IO Model $\mathrm{C}$ takes the form of:

$$
y_{t}=\mu+\theta D U_{t}+\beta t+\gamma D T_{t}+d D(T B)_{t}+\alpha y_{t-1}+\sum_{i=1}^{k} \Delta y_{t-i}+\varepsilon_{t} .
$$

Where $D(T B)$ represents a change in the level. $D U$ represents a change in the slope. $D T=t D U, t$ is the trend. Under the null hypothesis, $\mu \neq 0$ (in general), $\beta=0, \theta=0$ (except in Model C), $\gamma=0$, $d \neq 0$, and $\alpha=1$. Under the alternative hypothesis of trend-stationary, $\mu \neq 0, \beta \neq 0, \theta \neq 0$, $\gamma \neq 0$ (in general), $d=0$, and $\alpha<1$. The null is tested using the $t$-statistic for $\alpha=1$. The break date $T_{\mathrm{b}}$ is endogenously selected by minimizing the $t$-statistic for $\alpha=1$; the minimal is termed $t_{\alpha}^{*}$. It is worth noting that removing the dummy variable $D(T B)$ from Eq. 1, we obtain the Model B (the changing growth model):

$$
y_{t}=\mu+\theta D U_{t}+\beta t+\gamma D T_{t}+\alpha y_{t-1}+\sum_{i=1}^{k} \Delta y_{t-i}+\varepsilon_{t} .
$$

To increase the unit root test robustness, we also conducted both the augmented Dickey-Fuller (ADF) test [27-29] and the Phillips-Perron (PP) test [30-32]. It has been suggested that most macroeconomic series are integrated of order one $(I(1))[33]$.

\section{Data}

Data contained four monthly time series. We collected the series from the Orient Securities. The Orient Securities Co., Ltd. provides this trading system online. The online trading system software can be downloaded from <http://www.dfzq.com.cn/dfzq/i/orientsec-software.jsp $>$. The Shanghai Composite Index (SHANGHAI COMPOSITE INDEX) and the Shenzhen Component Index (SHENZHEN COMPONENT INDEX) cover the period of January 1992-December 2014. The property firm stock prices for Chongqing Yu Kai Fa (CHONGQING YU KAI FA) cover the period of January 1994-November 2014. The property-related firm stock prices for Sichuan Road and Bridge (SICHUAN ROAD) cover the period of January 2004-December 2014. Income from real 
estate in 2015 accounted for $80 \%$ of Chongqing Yu Kai Fa's total. Revenue from public infrastructure construction in 2015 accounted for $86 \%$ of Sichuan Road and Bridge's total. So, these two firms are closely related to the real estate sector. The stock prices or indices were the closing figures on the last trading day of each month. We plotted the log of the stock indices and the share prices for two firms (Fig. 1).

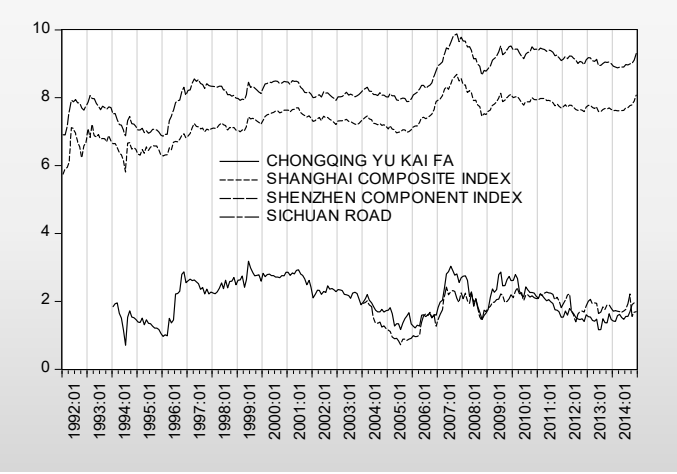

Figure 1. The log of stock price changes in the A-share markets in China

\section{Econometrical results}

The $t_{\alpha}^{*}$-statistics for SHANGHAI COMPOSITE INDEX and SHENZHEN COMPONENT INDEX were 27.99 and 42.66, respectively (Table 1), implying a break. The $t_{a}^{*}$-statistics for $C H O N G Q I N G$ $Y U K A I F A$ and SICHUAN ROAD were 31.59 and 7.93, respectively, also suggesting a break. Moreover, $\alpha<1, \beta \neq 0$ for all the four variables. Hence, the variables SHANGHAI COMPOSITE INDEX, SHENZHEN COMPONENT INDEX, CHONGQING YU KAI FA, and SICHUAN ROAD all included a break date in their respective stock index or price trend function. The break date $\left(T_{\mathrm{b}}\right)$ for SHANGHAI COMPOSITE INDEX, SHENZHEN COMPONENT INDEX, CHONGQING YU KAI $F A$, and SICHUAN ROAD were January 2007, February 2007, October 2001, and November 2008, respectively.

Table 1. Structural break tests (The Perron mixed model C)

\begin{tabular}{|l|l|l|l|l|}
\hline \multicolumn{1}{c}{ The log of variable } & \multicolumn{1}{c}{$\alpha\left(t_{a}^{*}\right)$} & \multicolumn{1}{c}{$\beta$ (t-statistic $)$} & \multicolumn{1}{c|}{$T_{b}$} \\
\hline SHANGHAI COMPOSITE INDEX & $0.86(27.99)$ & $0.00(2.80)$ & 2 & Jan 2007 \\
\hline SHENZHEN COMPONENT INDEX & $0.90(42.66)$ & $0.00(3.32)$ & 9 & Feb 2007 \\
\hline CHONQING YU KAI FA & $0.90(31.59)$ & $0.00(1.92)$ & 3 & Oct 2001 \\
\hline SICHUAN ROAD & $0.66(7.93)$ & $0.01(2.39)$ & 12 & Nov 2008 \\
\hline
\end{tabular}

Notes: The trimming fraction was suggested to be 0.15 [34]. Truncation lag orders $k$ (between 2 and 12) were selected using the data-dependent method $[23,35,36]$. $t$-statistic for the $k$ th term was greater than or equaled to 1.9 in absolute value. $T_{\mathrm{b}}$ was the break date detected. The critical values for $T=100$ were $-6.21,-5.55$, and -5.25 at the $1 \%, 5 \%$, and $10 \%$ levels, respectively [23].

Both the ADF and PP tests rejected the null hypothesis of a unit root for the variables SHANGHAI COMPOSITE INDEX, CHONGQING YU KAI FA, and SICHUAN ROAD (Table 2). Both the tests accepted the null hypothesis of a unit root for SHENZHEN COMPONENT INDEX. Thus, two unit-root tests consistently indicate that SHANGHAI COMPOSITE INDEX, CHONGQING YU KAI FA, and SICHUAN ROAD are a stationary process, i.e. I(0). Only SHENZHEN COMPONENT INDEX is integrated of order one, i.e. I(1). The unit root results supplied additional evidence for the presence of a break date for SHANGHAI COMPOSITE INDEX, CHONGQING YU KAI FA, and SICHUAN ROAD. However, the unit root result did not supply new evidence for the break date for SHENZHEN COMPONENT INDEX. 
Table 2. Unit root tests

\begin{tabular}{|c|c|c|c|c|}
\hline The log of variable & Lags & Level & Lags & First difference \\
\hline \multicolumn{5}{|c|}{$\mathrm{ADF}$} \\
\hline SHANGHAI COMPOSITE INDEX & 0 & $-3.84\left(-3.43^{* *}\right)$ & - & - \\
\hline SHENZHEN COMPONENT INDEX & 0 & $-2.31(-3.43 * *)$ & 8 & $-3.96(-3.43 * *)$ \\
\hline CHONQING YU KAI FA & 0 & $-4.46(-3.99 * * *)$ & - & - \\
\hline SICHUAN ROAD & 0 & $-4.55(-4.03 * * *)$ & - & - \\
\hline \multicolumn{5}{|c|}{ PP } \\
\hline SHANGHAI COMPOSITE INDEX & 6 & $-3.91\left(-3.43^{* *}\right)$ & - & - \\
\hline SHENZHEN COMPONENT INDEX & 7 & $-2.93(-3.43 * *)$ & 4 & $-14.11(-3.99 * * *)$ \\
\hline CHONQING YU KAI FA & 5 & $-4.59(-3.99 * * *)$ & - & - \\
\hline SICHUAN ROAD & 6 & $-5.11(-4.03 * * *)$ & - & - \\
\hline
\end{tabular}

Notes: Test equations included both the intercept and the trend according to [37]. Parentheses contain the critical values [27]. MacKinnon (1996) provides p-values [38]. *** denotes the $1 \%$ level and** the 5\% level. We used the modified AIC [39, 40] and Newey-West method [41] to select the lag length for ADF and PP, respectively.

\section{Concluding remarks}

The Perron tests indicate that over 1992-2014, a structural change in the Shanghai Composite Index occurred in January 2007, and in the Shenzhen Component Index in February 2007. Also, the Sichuan Road and Bridge firm stock prices and the Chongqing Yu Kai Fa property firm stock prices contain a break in November 2008 and October 2001, respectively. Thus, we conjecture that the November 2007 China Petroleum listing may cause the change. During the listing of China Petroleum between October and November 2007, A-share markets slumped twice: the Shanghai Composite Index plunged $4.80 \%$ on October 25 and $4.85 \%$ on November 8 , respectively. However, the breaks detected occurred in early 2007, about ten months sooner than the listing time. One reason may be that information on the listing event is entirely forecastable to institutional and individual investors, which has led to early trading based on the listing information. Hence, we cannot exclude the shock of the China Petroleum listing to the trend function.

Moreover, in February 2007, it is rumored that the Central Bank will tighten the market liquidity, and the Ministry of Finance National Tax Administration will levy the capital gains tax. With these rumors, the Shanghai Composite Index plunged 8.84\% on 27 February 2007. We surmise that the February 2007 fiscal and tax policy adjustment rumors may also cause the shift. However, our tests for the prices of two real estate firm stocks from Sichuan and Chongqing did not supply any evidence for this.

\section{Acknowledgement}

This research was financially supported by Sichuan Provincial Statistical Science Research Project (Project No. 2015sc52).

\section{References}

[1] G. Newell, K. W. Chau, S. K. Wong, K. McKinnell. Dynamics of the Direct and Indirect Real Estate Markets in China, J. Real Estate Portfol. Manage. 11 (2005) 263-279.

[2] Y. Yong Hong, B. Felmingham. First and Second Order Instability of the Shanghai and Shenzhen Share Price Indices, Appl. Econ. Letters. 13 (2006) 605-608.

[3] P. Perron. The Great Crash, the Oil Price Shock, and the Unit Root Hypothesis, Econometrica. 57 (1989) 1361-1401.

[4] E. F. Fama. Efficient Capital Markets: A Review of Theory and Empirical Work, J. Financ. 25 
(1970) 383-417.

[5] S. F. LeRoy. Efficient Capital Markets and Martingales, J. Econ. Lit. 27 (1989) 1583-1621.

[6] E. F. Fama. Efficient Capital Markets: Ii, J. Financ. 46 (1991) 1575-1617.

[7] E. M. Saunders Jr. Testing the Efficient Market Hypothesis without Assumptions, J. Portfol. Manage. 20 (1994) 28-30.

[8] Z. A. Ozdemir. Efficient Market Hypothesis: Evidence from a Small Open-Economy, Appl. Econ. 40 (2008) 633-641.

[9] G. M. Caporale, L. A. Gil-Alana. Fractional Integration and Mean Reversion in Stock Prices, Quart. Rev. Econ. Finance. 42 (2002) 599-609.

[10] V. Sonje, D. Alajbeg, Z. Bubas. Efficient Market Hypothesis: Is the Croatian Stock Market as (in)Efficient as the U.S. Market, Financial Theory and Practice. 35 (2011) 301-326.

[11] E. F. Renshaw. Stock Market Panics: A Test of the Efficient Market Hypothesis, Financial Analysts Journal. 40 (1984) 48-51.

[12] N. Al-Loughani, D. Chappell. On the Validity of the Weak-Form Efficient Markets Hypothesis Applied to the London Stock Exchange, Appl. Finan. Econ. 7 (1997) 173-176.

[13] E. Dockery, M. G. Kavussanos. Testing the Efficient Market Hypothesis Using Panel Data, with Application to the Athens Stock Market, Appl. Econ. Letters. volume 3 (1996) 121-123.

[14] M. T. Suleman, K. Hamid, S. Z. Ali Shah, R. S. Imdad Akkash. Testing the Weak Form of Efficient Market Hypothesis: Empirical Evidence from Asia-Pacific Markets, International Research Journal of Finance \& Economics. 58 (2010) 121-133.

[15] K.-C. Cheung, J. A. Coutts. A Note on Weak Form Market Efficiency in Security Prices: Evidence from the Hong Kong Stock Exchange, Appl. Econ. Letters. 8 (2001) 407-410.

[16] N. Groenewold. Share Market Efficiency: Tests Using Daily Data for Australia and New Zealand, Appl. Finan. Econ. 7 (1997) 645-657.

[17] N. Groenewold, K. C. Kang. The Semi-Strong Efficiency of the Australian Share Market, Econ. Rec. 69 (1993) 405-410.

[18] T. Evans. Efficiency Tests of the Uk Financial Futures Markets and the Impact of Electronic Trading Systems, Appl. Finan. Econ. 16 (2006) 1273-1283.

[19] L. J. Christiano. Searching for Breaks in Gnp, J. Bus. Econ. Statist. 10 (1992) 237-250.

[20] E. Zivot, D. W. K. Andrews. Further Evidence on the Great Crash, the Oil-Price Shock, and the Unit-Root Hypothesis, J. Bus. Econ. Statist. 10 (1992) 251-270.

[21] P. Perron, T. J. Vogelsang. Nonstationarity and Level Shifts with an Application to Purchasing Power Parity, J. Bus. Econ. Statist. 10 (1992) 301-320.

[22] J. Lee, M. C. Strazicich. Break Point Estimation and Spurious Rejections with Endogenous Unit Root Tests, Oxford Bulletin of Economics \& Statistics. 63 (2001) 535-558.

[23] P. Perron. Further Evidence on Breaking Trend Functions in Macroeconomic Variables, J. Econometrics. 80 (1997) 355-385.

[24] S. Popp. New Innovational Outlier Unit Root Test with a Break at an Unknown Time, Journal of Statistical Computation \& Simulation. 78 (2008) 1143-1159.

[25] T. J. Vogelsang, P. Perron. Additional Tests for a Unit Root Allowing for a Break in the Trend Function at an Unknown Time, International Economic Review. 39 (1998) 1073-1100.

[26] A. Sen. On Unit-Root Tests When the Alternative Is a Trend-Break Stationary Process, J. Bus. 
Econ. Statist. 21 (2003) 174-184.

[27] D. A. Dickey, W. A. Fuller. Distribution of the Estimators for Autoregressive Time Series with a Unit Root, J. Amer. Stat. Assoc. 74 (1979) 427-431.

[28] W. A. Fuller, Introduction to Statistical Time Series, John Wiley, New York, 1976.

[29] D. A. Dickey, D. P. Hasza, W. A. Fuller. Testing for Unit Roots in Seasonal Time Series, J. Amer. Stat. Assoc. 79 (1984) 355-365.

[30] P. C. B. Phillips, P. Perron. Testing for a Unit Root in Time Series Regression, Biometrika. 75 (1988) 335-346.

[31] J. Y. Park, P. C. Phillips. Statistical Inference in Regressions with Integrated Processes: Part 2, Econometric Theory. 5 (1989) 95-131.

[32] P. C. Phillips. Regression Theory for near-Integrated Time Series, Econometrica. (1988) 10211043.

[33] C. R. Nelson, C. I. Plosser. Trends and Random Walks in Macroeconomic Time Series, J. Monet. Econ. 10 (1982) 139-162.

[34] A. Banerjee, R. L. Lumsdaine, J. H. Stock. Recursive and Sequential Tests of the Unit Root and Trend Break Hypothesis: Theory and International Evidence, J. Bus. Econ. Statist. 10 (1992) 271-287.

[35] S. Ng, P. Perron. Unit Root Tests in Arma Models with Data Dependent Methods for the Selection of the Truncation Lag, J. Amer. Stat. Assoc. 90 (1995) 268-281.

[36] S. Ng, P. Perron. Lag Length Selection and the Construction of Unit Root Tests with Good Size and Power, Econometrica. 69 (2001) 1519-1554.

[37] D. F. Hendry, K. Juselius. Explaining Cointegration Analysis: Part I, Energy J. 21 (2000) 1-42.

[38] J. G. MacKinnon. Numerical Distribution Functions for Unit Root and Cointegration Tests, J. Appl. Econometrics. 11 (1996) 601-618.

[39] B. Mainassara. Selection of Weak Varma Models by Modified Akaike's Information Criteria, J. Time Ser. Anal. 33 (2012) 121-130.

[40] N. S., P. P., Lag Length Selection and the Construction of Unit Root Tests with Good Size and Power, 1997.

[41] W. K. Newey, K. D. West. A Simple, Positive Semi-Definite, Heteroskedasticity and Autocorrelation Consistent Covariance Matrix, Econometrica. 55 (1987) 703-708. 